\title{
Miniseries of reviews: gynecological pathology
}

\author{
Sigurd F. Lax ${ }^{1}$ \\ Published online: 4 June 2018 \\ (C) Springer-Verlag GmbH Germany, part of Springer Nature 2018
}

Virchows Archiv will regularly publish issues with a coordinated set of reviews in areas with important recent developments, but in volume insufficient to make it into a full review issue. This issue contains such a miniseries of three review articles in the area of gynecological pathology, two of which are dealing with novel developments in molecular pathology and histopathology of the uterus while the third addresses the diagnostically challenging subject of benign proliferations of the endometrium.

Goebel et al. (https://doi.org/10.1007/s00428-017-2279-8) describe the evolution of the classification of endometrial carcinoma, which used to be purely descriptive but is now molecularly based, as a result of the rapid development of molecular pathology [1]. They present a snap-shot of the current state of the art of molecular pathology of the endometrium as well as a vision on putative further developments, following integration of new knowledge emerging from molecular studies into diagnostic pathology. Based on the results of molecular analysis of endometrial carcinoma in the context of The Cancer Genome Atlas (TCGA) project and using immunohistochemistry and sequencing technologies, a diagnostic algorithm was developed which allows recognition of carcinoma types beyond histology with distinct biological behaviour [2]. This replaces a purely histopathological classification by one that is more molecularly based, comparable to what has happened in breast and lung cancer. This new classification will provide more precise prognostic information as well as predictive information to guide targeted therapy [3, 4]. Although most endometrial carcinomas do not need systemic treatment, molecular classification goes beyond histology in defining tumour subtypes with excellent prognosis, such as those with a DNA polymerase $\varepsilon$ (POLE) domain mutation, or

Sigurd F. Lax

sigurd.lax@medunigraz.at; sigurd.lax@kages.at

1 Department of Pathology, Hospital Graz Süd-West, Göstingerstrasse 22, AT-8020 Graz, Austria with poor prognosis, such as the mixed endometrial carcinomas with a "low-grade" serous-like component, which will both profit from a "tailored" approach to treatment. The TCGA data segregated endometrial carcinoma into four prognostic categories, but this is not in conflict with the traditional type 1 and type 2 endometrial carcinoma [1] as it only identifies one further subtype, the small group of POLE mutated carcinomas which have an excellent prognosis. The microsatellite instable and the low copy number alteration groups cluster together, since they show similar prognosis and represent the two major pathways involved in type 1 carcinomas, whereas the high copy number alteration serous-like carcinomas represent the type 2 carcinomas. The two type model as originally proposed by Bokhman was based on clinical features and biology. POLE mutated carcinomas fit well in type 1 endometrial carcinomas but further clinicopathological and molecular correlations will await data from additional studies [5, 6]. The strength of an updated molecular model for endometrial carcinoma is its increased clinical impact with transition from bench and lecture hall to bedside. The biggest challenge will be implementation of this novel diagnostic algorithm into daily practice, particularly in tertiary centres and low income countries [7].

In contrast to endometrial carcinoma, a molecular signature with prognostic impact has as yet not been identified for endocervical adenocarcinoma. Instead, it has been found that the the biology of endocervical adenocarcinomas is reflected in its pattern of growth (https://doi.org/10.1007/s00428-0182312-6). Three growth patterns, known as Silva patterns (named after the senior author of the first description, Elvio Silva), have been described (non-destructive, focally destructive and diffusely destructive) [8,9], which reportedly correlate with the frequency of lymph node metastases and local recurrence and will have strong impact on treatment. Knowledge about this growth pattern-based classification has been further broadened in recent years by several multicenter international collaborative studies. This pattern-based model seems simple but is a rather smart 
approach to cervical tumour pathology, needs to become generally applied in diagnostic pathology and therefore has been adopted by the European working group responsible for the new guidelines for diagnosis and treatment of cervical cancer. The great merit of this system is its recognition of a subgroup of carcinoma with "smooth" nondestructive infiltration irrespective of its size, which requires less aggressive surgical treatment [9]. Future prospective randomized trials will be necessary to finally implement this pattern-based classification.

The third paper deals with benign endometrial proliferations mimicking malignant neoplasms (https://doi.org/10. 1007/s00428-018-2314-4). This is a challenging issue, in particular on small biopsies. The paper focuses on differential diagnostic problems associated with unusual endometrial lesions, such as papillary and mucinous proliferations, clear cell and secretory changes and uncommon patterns of endometrial polyps. Most of these lesions have been recognized a long time ago while some are of more recent date, but they are infrequent which may cause diagnostic problems, in particular when it comes to differentiating them from malignant lesions [10]. Some of the lesions may be associated with hormonal treatment or altered endogenous hormone levels, and sufficient clinical information will be crucial for a correct diagnosis but is often lacking. The recognition of the benign nature of a lesion is particularly important for those women who desire to have children, and for whom hysterectomy is to be avoided. The author provides a practical approach with tips for a correct diagnosis and adequate use of immunohistochemistry. These diagnostic challenges represent a great responsibility for pathologists to provide and even improve high diagnostic skills with the goal to help the patient in the best possible way. It is our aim as a pathology journal to support the pathology community in this effort.

\section{References}

1. Lax SF (2004) Molecular genetic pathways in various types of endometrial carcinoma: from a phenotypical to a molecular-based classification. Virchows Arch 444(3):213-223
2. Cancer Genome Atlas Research N, Kandoth C, Schultz N, Cherniack AD, Akbani R, Liu Y, Shen H, Robertson AG, Pashtan I, Shen R, Benz CC, Yau C, Laird PW, Ding L, Zhang W, Mills GB, Kucherlapati R, Mardis ER, Levine DA (2013) Integrated genomic characterization of endometrial carcinoma. Nature 497(7447):6773. https://doi.org/10.1038/nature12113

3. Travis WD, Brambilla E, Riely GJ (2013) New pathologic classification of lung cancer: relevance for clinical practice and clinical trials. J Clin Oncol 31(8):992-1001. https://doi.org/10.1200/JCO. 2012.46.9270

4. Vuong D, Simpson PT, Green B, Cummings MC, Lakhani SR (2014) Molecular classification of breast cancer. Virchows Arch 465(1):1-14. https://doi.org/10.1007/s00428-014-1593-7

5. Bokhman JV (1983) Two pathogenetic types of endometrial carcinoma. Gynecol Oncol 15(1):10-17

6. Lax SF, Kurman RJ (1997) A dualistic model for endometrial carcinogenesis based on immunohistochemical and molecular genetic analyses. Verh Dtsch Ges Pathol 81:228-232

7. Talhouk A, McConechy MK, Leung S, Li-Chang HH, Kwon JS, Melnyk N, Yang W, Senz J, Boyd N, Karnezis AN, Huntsman DG, Gilks CB, McAlpine JN (2015) A clinically applicable molecularbased classification for endometrial cancers. Br J Cancer 113(2): 299-310. https://doi.org/10.1038/bjc.2015.190

8. Diaz De Vivar A, Roma AA, Park KJ, Alvarado-Cabrero I, Rasty G, Chanona-Vilchis JG, Mikami Y, Hong SR, Arville B, Teramoto N, Ali-Fehmi R, Rutgers JK, Tabassum F, Barbuto D, AguileraBarrantes I, Shaye-Brown A, Daya D, Silva EG (2013) Invasive endocervical adenocarcinoma: proposal for a new pattern-based classification system with significant clinical implications: a multi-institutional study. Int J Gynecol Pathol 32(6):592-601. https://doi.org/10.1097/PGP.0b013e31829952c6

9. Roma AA, Mistretta TA, Diaz De Vivar A, Park KJ, AlvaradoCabrero I, Rasty G, Chanona-Vilchis JG, Mikami Y, Hong SR, Teramoto N, Ali-Fehmi R, Barbuto D, Rutgers JK, Silva EG (2016) New pattern-based personalized risk stratification system for endocervical adenocarcinoma with important clinical implications and surgical outcome. Gynecol Oncol 141(1):36-42. https:// doi.org/10.1016/j.ygyno.2016.02.028

10. Nucci MR, Prasad CJ, Crum CP, Mutter GL (1999) Mucinous endometrial epithelial proliferations: a morphologic spectrum of changes with diverse clinical significance. Mod Pathol 12(12): $1137-1142$ 